\title{
ШВАННОМЫ СЕРАЦА
}

\author{
И.М. Ильинский ${ }^{1,2}$, А.С. Иванов ${ }^{1}$ Н.П. Можейко ${ }^{1}$, М.К. Луговский \\ 1 ФГБУ «Национальный меАицинский исслеАовательский центр трансп^антологии и искусственных \\ органов имени акалемика В.И. Шумакова» Минздрава России, Москва, Российская Фелерация \\ 2 ФГАОУ ВО «Первый МОскОВский госуАарственный меАицинский университет имени \\ И.М. Сеченова» Минзарава России (Сеченовский университет), Москва, Российская Федерация
}

\begin{abstract}
Первичные опухоли сердца представлены многочисленными морфологическими формами. Одной из самых редких форм является шваннома сердца. Она представляет собой опухоль из клеток шванна, который продуцирует миелин оболочек периферических нервов. Частота их встречаемости от 0,02 до 0,056\% от всех первичных опухолей. Впервые шваннома была описана в 1972 году и по настоящий момент является предметом пристального изучения клиницистов и морфологов, что связано с редкостью диагностики и с особенностями гистологического строения. В настоящее время, по данным литературы, в мире диагностировано 23 шванномы сердца, из которых 8 определялись в правом предсердии. В процессе исследования данного типа опухолей в 1920 году шведским ученым N. Antoni были определены два типа опухолей в зависимости от типа клеточной архитектуры (тип А и тип В). Тип А состоит из веретенообразных клеток в виде пучков, а тип В - из клеток полиглональной формы с обильной цитоплазмой, и располагаются они не плотно. Также помимо определения специфических клеток диагноз «шваннома» может быть подтвержден в связи с сильным диффузным равномерным окрашиванием белка S100. Единственным методом лечения является хирургическая коррекция в соответствии с правилами онкологической хирургии с замещением образовавшегося вследствие резекции опухоли дефицита тканей различными биологическими и синтетическими материалами. При невозможности выполнения полного иссечения опухоли единственным методом лечения является выполнение трансплантации сердца
\end{abstract}

Ключевые слова: шваннома сердиа, опухоль сердияа, кардиоонкология.

\section{HEART SCHWANNOMA}

\author{
I.M. Iljinsky ${ }^{1,2}$, A.S. Ivanov ${ }^{1}$, N.P. Mogeiko ${ }^{1}$, M.K. Lugovskiy ${ }^{1}$ \\ ${ }^{1}$ V.I. Shumakov National Medical Research Center of Transplantology and Artificial Organs \\ of the Ministry of Healthcare of the Russian Federation, Moscow, Russian Federation \\ ${ }^{2}$ I.M. Sechenov First Moscow State Medical University of the Ministry of Healthcare \\ of the Russian Federation (Sechenovsky University), Moscow, Russian Federation
}

\begin{abstract}
Primary tumors of the heart are presented by different morphological types. One of the rarest forms is a schwannoma of the heart. It consists of the Schwann cells or neurolemmocytes, which produces the myelin constituent of peripheral nerves. Frequency is from 0.02 to $0,056 \%$ of all primary tumors. First time it was described in 1972 and it is currently the subject of intense study by clinicians and morphologists, which is associated with the extreme rare diagnostic and peculiarities of the histological structure. Thus far 23 cases of this disease have been reported in the literature, 8 of them located primarily in the right atrium. During the study of this type of tumor in 1920, the Swedish scientist N. Antoni identified two types of tumors depending on the type of cellular architecture (type A and type B). Type A consists of spindle-shaped cells in the form of bundles, and type B consists of polygonal cells with abundant cytoplasm and they are not tightly arranged. Also, in addition to identifying specific cells, the diagnosis of schwannoma can be confirmed due to the strong diffuse staining of the S100 protein. The only method of treatment is surgical correction with the replacement of the tissue deficit with various biological and synthetic materials after tumour resection. If it is impossible to perform a complete excision of the tumor, heart transplant is the only kind of treatment.
\end{abstract}

Key words: heart schwannoma, heart tumors, cardiac oncology.

Для корреспонденции: Луговский Максим Константинович. Адрес: 123182, Москва, ул. Щукинская, д. 1.

Тел. (926) 590-62-05. E-mail: lugovskiymax@gmail.com

For correspondence: Lugovskiy Maksim Konstantinovich. Address: 1, Shchukinskaya str., Moscow, 123182, Russian Federation.

Tel. (926) 590-62-05. E-mail: lugovskiymax@gmail.com 
Кардиоонкология, термин, введенный в литературу Б.В. Петровским в 1997 г. [2], в настоящее время прочно вошла в одно из направлений кардиохирургии и трансплантологии. Многообразие морфологических форм первичных опухолей сердца, их объем и возможность прорастания стенок сердца делает необходимым использование трансплантации сердца как радикального метода лечения.

Данный литературный обзор посвящен крайне редкой назологической форме новообразований сердца - шванноме.

Шванномы (синонимы: неврилеммома, невринома) - это опухоли из клеток Шванна, которые продуцируют миелин оболочек периферических нервов [40]. Они представляют собой первичные нейрогенные новообразования и могут развиваться в любой части тела [36]. Главным образом шванномы возникают в области головы и шеи. Они могут также присутствовать в грудной клетке, преимущественно в заднем средостении и очень редко в среднем средостении [46].

Непосредственно в сердце шванномы встречаются крайне редко [39], они составляют от 0,02 до $0,056 \%$ от всех неоплазм [35]. Шванномы почти всегда доброкачественные, хотя описаны первично злокачественными [16] и метастатическими опухолями [18]. Считают, что они возникают из клеток оболочек кардиальных ветвей блуждающего нерва и сердечного сплетения $[16,29]$.
Тщательное гистологическое и иммуногистохимическое исследование шванном имеет большое клиническое значение, так как у них имеется, хотя и минимальный, потенциал трансформации в злокачественную форму. При росте даже доброкачественных шванном могут появиться клинические признаки сдавливания смежных структур - крупных сосудов, полостей сердца, медиастинальных структур и коронарных артерий.

Эпидемиология. Шванномы встречаются в любом возрасте, с пиковой частотой между третьим и шестым десятилетием. В одном из обзоров литературы [15] возраст пациентов колебался от 12 до 72 лет. Отсутствуют половые различия в частоте этих опухолей, но в исследовании [15] шванномы преобладали у женщин - в $71 \%(\mathrm{n}=10)$ наблюдений.

Первое сообщение о доброкачественной шванноме сердца относится к 1972 году (табл. 1). Эта опухоль представляла собой 1,5-сантиметровый инкапсулированный узелок в стенке правого предсердия с типичными гистологическими особенностями опухоли нейрогенного происхождения. С тех пор каждое наблюдение шванномы сердца становилось предметом публикации.

Bizzarri et al. нашли в литературе восемь случаев первичной неврилеммомы сердца [4], a Jassal et al. только пять наблюдений первичной шванномы сердца по Медлайну за период с 1966-го по 2002 год [20].

Таблица 1

\section{Доброкачественные шванномы сердца}

Benign schwannomas of the heart

\begin{tabular}{|c|l|l|c|c|}
\hline № & \multicolumn{1}{|c|}{ Автор и год публикации } & \multicolumn{1}{|c|}{ Локализация } & Пол & Возраст \\
\hline 1 & Gleason T.H. et al., 1972 & Правое предсердие & - & - \\
\hline 2 & Monroe B. et al., 1984 & Правое предсердие & М & 70 \\
\hline 3 & Forbes A.D. et al., 1994 & Левое предсердие & М & 35 \\
\hline 4 & Hashimoto T. et al., 1998 & Перикард & Ж & 46 \\
\hline 5 & Bizzarri F. et al., 2001 & Правое предсердие & М & 72 \\
\hline 6 & Jassal D.S. et al., 2003 & Правое предсердие & Ж & 49 \\
\hline 7 & Sirlak M. et al., 2003 & Левое предсердие & Ж & 61 \\
\hline 8 & Nakamura K. et al., 2003 & Правое предсердие & Ж & 56 \\
\hline 9 & Stolf N.A. et al., 2006 & Правое предсердие & М & 57 \\
\hline 10 & Early S.A. et al., 2007 & Правое предсердие & - & - \\
\hline 11 & La Francesca S. et al., 2007 & Левый желудочек & Ж & 57 \\
\hline 12 & Sevimli S. et al., 2007 & Левый желудочек & Ж & 38 \\
\hline 13 & Rajesh G.N. et al., 2013 & Перикард & Ж & 50 \\
\hline 14 & Zhang X.H. et al., 2013 & Перикард & М & 35 \\
\hline 15 & Chung J.H. et al., 2014 & Перикард & Ж & 55 \\
\hline 16 & Hwang S.K., Jung S.Н., 2014 & Левое предсердие & Ж & 69 \\
\hline 17 & Jung J.C. et al., 2015 & Межпредсердная перегородка & Ж & 42 \\
\hline 18 & Son K.H. et al., 2015 & Межпредсердная перегородка & Ж & 48 \\
\hline 19 & Yun P.J. et al., 2016 & Перикард & Ж & 47 \\
\hline 20 & Koujanian S. et al., 2017 & С пр. предсердия на пр. желудочек & М & 30 \\
\hline 21 & Almobarak A.A. et al., 2018 & Перикард & Ж & 73 \\
\hline 22 & Coбственное наблюдение, 2019 & Правое предсердие &
\end{tabular}


По данным Stolf et al., к году публикации зарегистрировано всего 10 случаев шванномы сердца [43]. $\mathrm{B}$ более поздней работе сообщается уже о 14 доброкачественных шванномах предсердий [15]. Hwang и Jung в литературе зафиксировали 16 наблюдений первичной шванномы сердца [17]. Almobarak et al. в англоязычной литературе выявили всего 24 наблюдения шванном сердца: шваннома непосредственно в стенке сердца $(\mathrm{n}=18)$ и перикардиальная шваннома $(\mathrm{n}=6)[3]$.

Локализация доброкачественных шванном. Большинство шванном локализуются на правой стороне сердца и находятся в непосредственной близости от межпредсердной перегородки, прорастая в стенку правого предсердия и межпредсердную перегородку (табл. 1). Первичные шванномы сердца возникают из миелинизированных нервов, расположенных в жировой клетчатке эпикарда. Эти нервы в основном расположены в области правых отделов сердца, особенно в области правого предсердия и близко к сердечному сплетению. Однако шванномы могут быть и в левом предсердии, вблизи устьев легочных артерий или в атриовентрикулярной борозде [43]. По мнению Hwang и Jung, в сердце шванномы с одинаковой частотой локализуются в правом или левом предсердии, но реже могут быть и в других отделах сердца [17].

Небольшое количество наблюдений доброкачественных шванном было зарегистрировано в перикарде [49]. Здесь они встречаются еще реже, чем непосредственно в сердце, и составляют от 6,7 до $12,8 \%$ всех опухолей в области сердца. Перикардиальные шванномы возникают также из кардиальных ветвей блуждающего нерв или из сердечного сплетения [16, 17]. Ниже мы приводим краткое описание доброкачественных и злокачественных шванном, растущих из различных отделов сердца.

Доброкачественные шванномы правого предсердия. У 72-летнего мужчины, который обратился с жалобами на появившуюся прогрессирующую одышку и боль в грудной клетке, семь лет тому назад была выполнена правосторонняя нефрэктомия по поводу аденокарциномы почки. Обследование выявило опухоль правого предсердия. Она была удалена хирургическим путем. Морфологическое исследование определило опухоль как первичную неврилеммому правого предсердия [4].

У 49-летней женщины при эхокардиографии и магнитно-резонансной томографии в правом предсердии было выявлено образование размером $5 \times$ 3 см. В условиях искусственного кровообращения из полости правого предсердия было удалено образование, расположенное в области атриовентрикулярной борозды. Макроскопически опухоль была инкапсулирована, имела яйцевидную форму размерами $6,4 \times 5,5 \times 3,4$ см, массой 70,9 г. Поверхность разреза имела неоднородный желто-беловатый цвет. Микроскопическое исследование показало, что опухоль состоит из веретенообразных опухолевых клеток с эозинофильной цитоплазмой и удлиненными ядрами. На основании гистологического и иммуногистохимического исследования был поставлен диагноз «доброкачественная шваннома правого предсердия» [20].

B сообщении Stolf et al. описывается случай выявления у 56-летней женщины на рентгенограмме грудной клетки аномального силуэта правого отдела сердца. Компьютерная томография показала в стенке правого предсердия неоднородную плотную опухолевую массу с кальцификатами [43]. Опухоль сдавливала правое предсердие и верхнюю полую вену. В условиях искусственного кровообращения на работающем сердце выполнено радикальное удаление опухоли. Стенка правого предсердия была реконструирована с помощью заплаты из ксеноперикарда. Инкапсулированная опухоль имела яйцевидную форму, была размером $6,0 \times 4,8$ см и массой 67 г, коричневого и красноватого цвета, с белыми и желтыми полосками на разрезе, плотно-эластической консистенции с небольшими кальцинированными участками. Микроскопически имело место смешанное строение, состоящее как из участков типа А по Антони (тельца Верокаи), так и участков типа В по Антони (фасцикулярный тип). Диагноз: доброкачественная шваннома правого предсердия.

В 1920 году Нилс Рагнар Эжен Антони (Nils Ragnar Eugène Antoni, 1887-1968), шведский исследователь, работавший в Королевской неврологической клинике Стокгольма, впервые описал в опухолях оболочки периферических нервов, которые позднее стали известны как шванномы, два различных типа клеточной архитектуры. Эти области более поздними авторами были названы как тип Антони А и тип Антони В [48].

Тип Антони А состоял из веретенообразных клеток, которые были плотно размещены в виде пучков. Их ядра имели вид палисада. Митозы отсутствовали. В типе Antoni В клетки располагались не плотно, а были редкими. Они имели полигональную форму с обильной цитоплазмой, цитоплазматическими липидами и круглыми или овальными ядрами. В опухолевых клетках обильно присутствовал белок S-100, специфическая гистохимическая окраска, подтверждающая доброкачественность шванномы [50].

У 57-летнего мужчины при проведении трансторакальной эхокардиографии было выявлено объемное образование в правом предсердии. Пациент отрицал наличие каких-либо сердечно-сосудистых симптомов. Электрокардиография и рентгеноскопия грудной клетки патологии не выявили. При магнитно-резонансной томографии сердца было обнаружено образование размерами 4,3 × 5,2 см в области 
заднелатеральной стенки правого предсердия, распространяющееся к утолщенной межпредсердной перегородке. Это образование стенозировало просвет верхней полой вены на 50\%. Ангиография продемонстрировала нормальную функцию левого желудочка и коронарных артерий, с выбуханием опухоли в правое предсердие. Была заподозрена миксома предсердная. Во время операции на боковой стенке правого предсердия было обнаружено образование размерами $8 \times 8$ см, плотно-эластической консистенции, напоминающей резину. Это образование находилось вне полости сердца - располагалось в пределах перикарда и простиралось к правой верхней легочной вене. Последующее микроскопическое исследование показало, что удаленная опухоль представляет собой шванному правого предсердия с низким митотическим индексом. Диагноз «шваннома» был подтвержден в связи с сильным диффузным равномерным окрашиванием белка S100 [15].

Сорокасемилетняя женщина, в анамнезе которой был рак яичников, стала замечать периодическую резкую боль в груди, одышку при подъеме по лестнице (NYHA I или II), а также несколько эпизодов сердцебиения в течение месяца, длящихся 2-3 минуты. При обследовании была обнаружена опухоль сердца, которая располагалась между правым предсердием и правым желудочком. Интраоперационно было обнаружено, что кровоснабжение опухоли осуществляется из ветви правой коронарной артерии и задней нисходящей артерии. Операция была проведена успешно и состояла из резекции опухоли, перевязки задней нисходящей артерии и аутовенозного аорто-коронарного шунтирования задней нисходящей артерии. Макроскопически опухоль была яйцевидной формы, размерами 9,0 × 7,0 × 6,5 см, массой 160 г. Наружная поверхность дольчатая, гладкая, серо-коричневого цвета. Микроскопическое исследование показало, что опухоль заключена в толстую фиброзную капсулу. Она имела типичное гистологическое строение доброкачественной шванномы. Иммуногистохимическое исследование подтвердило диагноз: клетки опухоли были с выраженной позитивной реакцией на белок S100 и отрицательной реакцией на десмин, кальретинин, кальдесмон и альфа актин гладкомышечных клеток [22].

Доброкачественные шванномы межпредсердной перегородки. Jung et al. сообщили о бессимптомной внутрисердечной шванноме у 69-летней женщины, которая проходила обследование по поводу рака сигмовидной кишки. Эхокардиография и магнитно-резонансная томография сердца показали, что в левом предсердии имеется образование размерами 2,5 × 2,6 см, которое широким основанием прикреплялось к межпредсердной перегородке. Подвижность опухоли была незначительной. Дисфункция клапанов и гемодинамические нарушения отсутствовали. Первоначальный диагноз - миксома. Ее удаление было запланировано до операции по поводу рака толстой кишки. Операцию проводили через срединную стернотомию. Использовали стандартную канюляцию восходящей аорты и двухкавальную венозную канюляцию. Применялась только антеградная кардиоплегия, поскольку опухоль располагалась очень близко к коронарному синусу. При пальпации с нижней стороны сердца вблизи коронарного синуса ощущалась твердая масса. После пережатия аорты выполнена правосторонняя и левосторонняя атриотомия. Опухоль не была видна в полостях предсердий. Поэтому был использован доступ через межпредсердную перегородку, в которой было обнаружено инкапсулированное образование размером 2,5 см. В связи с такой локализацией при удалении опухоли особое внимание уделялось предотвращению повреждения коронарного синуса. Макроскопически опухоль представляла собой инкапсулированное кистозное образование размерами $2,8 \times 2,7 \times 2,5$ см. На поверхности разреза были видны несколько кист. Гистологическая и иммуногистохимическая картина типичны для доброкачественной шванномы сердца. Пациентка выписана на 10-е сутки после операции без осложнений. Через один месяц после удаления шванномы сердца ей выполнили операцию по поводу рака толстой кишки [21].

Son et al. описали доброкачественную шванному в межпредсердной перегородке у 42-летней женщины. Трансторакальная эхокардиография и компьютерная томография грудной клетки показали наличие в перикарде огромной массы, которая деформировала правое и левое предсердия, верхнюю полую и верхнюю правую легочную вены. В связи с тем, что отсутствовала ясность в вопросе о месте возникновения опухоли (либо из стенки сердца, либо из средостения), для более четкого планирования операции была выполнена 3D-печать сердца. Использование модели печатного сердца позволило найти оптимальный хирургический подход. Опухоль успешно была резецирована в условиях искусственного кровообращения с доступом через срединную стернотомию. Опухоль размером $14 \times 10 \times 7$ см, весом 370 г, была дольчатой, инкапсулированной, желтого цвета, с кровоизлияниями. На основании гистологического и гистохимического исследования был поставлен диагноз «доброкачественная шваннома межпредсердной перегородки» [41].

Представляет интерес наблюдение, в котором при патологоанатомическом вскрытии у 70-летнего мужчины, страдавшего аденокарциномой легких с множественными метастазами в лимфатические узлы и другие органы, была обнаружена доброкачественная неврилеммома сердца. Исследование в световом микроскопе показало наличие в неврилем- 
моме сердца маленького метастатического узелка аденокарциномы. Электронно-микроскопическое исследование подтвердило происхождение опухоли сердца из шванновских клеток [27].

Доброкачественные шванномы левого предсердия. У 35 -летнего мужчины с фибрилляцией предсердий была выявлена первичная доброкачественная шваннома левого предсердия. После удаления опухоли в условиях искусственного кровообращения большой дефект $\left(20 \mathrm{~cm}^{2}\right)$ задней стенки левого предсердия был закрыт заплатой из перикарда [11].

У 61-летней женщины было обнаружено образование, прилегающее к левому предсердию. Опухоль была резецирована с небольшим фрагментом стенки левого предсердия. Гистологический диагноз - доброкачественная шваннома левого предсердия [39].

У 55-летней женщины, в анамнезе которой в течение четырех последних лет в состоянии покоя были боли в груди, обнаружена опухоль левого предсердия. Макроскопически удаленная опухоль представляла собой яйцевидное образование размерами 4,3 $\times 4 \times 3 \mathrm{~cm}$, розовато-желтого цвета. Поверхность разреза была с очаговым некрозом и кистами. На основании гистологического исследования поставлен диагноз «первичная шваннома левого предсердия» [17].

Доброкачественные шванномы перикарда. Некоторые шванномы растут из перикарда. Так, у 46-летней женщины на рентгенограмме грудной клетки было увеличение размеров сердца. Дальнейшее обследование установило наличие массивной интраперикардиальной опухоли размером $12 \times 8 \times$ 7 см. Во время операции в условиях искусственного кровообращения установлено, что опухоль плотно прилегала как к верхней полой вене, так и к правому предсердию. Патогистологический диагноз - неврилеммома [16].

У 38 -летней женщины была типичная нестабильная стенокардия с сопровождающим повышением содержания тропонина крови. На электрокардиограмме отмечена депрессия сегмента ST в отведениях V1 V4. Эхокардиография и компьютерная томография выявили в перикарде большие массы, деформирующие левое предсердие и левый желудочек. При коронарографии и компьютерной томографии отмечено смещение и сдавливание основного ствола левой коронарной артерии и ее огибающей ветви. Во время операции удалена интраперикардиальная опухоль, которая была «хорошо» инкапсулирована, а на ее разрезе обнаружен тромб. Гистологически опухоль соответствовала доброкачественной шванноме, что подтверждалось положительной окраской белка $\mathrm{S}$ 100 [34]. По мнению авторов, их презентация является единственной, при которой доброкачественная шваннома сочеталась с острым коронарным синд- ромом в результате деформации коронарного русла образованием.

У 50-летней китаянки были жалобы на кашель с небольшим количеством мокроты. Компьютерная томография (КТ) показала наличие в средостении дольчатых масс размером $9 \times 11 \mathrm{~cm}$, с острыми краями и точечными кальцификатами. Была выполнена торакотомия и радикальная резекция опухоли. Патоморфологическое исследование показало, что удаленное образование является доброкачественной перикардиальной шванномой. Опухоль была представлена двумя типами: Антони А и Антони В. Авторы считают, что представленное ими наблюдение является первым зарегистрированным случаем доброкачественной перикардиальной шванномы, расположенной в предтрахеальном пространстве и аортопульмональном окне.

Chung et al. сообщили об интраперикардиальной опухоли и тимоме у 35 -летнего мужчины. Была выполнена резекция обеих опухолей без искусственного кровообращения, через срединную стернотомию. Морфологическое исследование показало, что интраперикардиальная опухоль является шванномой с положительной окраской белка S-100 [7].

Тридцатилетний пациент жаловался на постепенно прогрессирующие боли в левой половине груди в течение шести месяцев. У него в анамнезе были приступы панического страха и пароксизмальной тахикардии, потливость и раздражительность. Компьютерная томография грудной клетки выявила интраперикардиальное образование $3 \times 2$ см, в проекции левого предсердия. Магнитно-резонансная томография сердца показала образование размером 2,5 $\times 2,5$ см, которое располагалось впереди пищевода и сдавливало правую ветвь легочной артерии. Пациента направили на операцию по удалению интраперикардиальной опухоли. Гистологическое исследование показало, что удаленная опухоль является перикардиальной шванномой. Микроскопически шваннома состояла из мономорфных веретенообразных клеток Шванна, расположенных в коллагеновой строме. Цитоплазма клеток Шванна слабо эозинофильная, а их ядра базофильные. Области, характерные для Антони В, состояли из редких клеток Шванна со слабо окрашенной цитоплазмой. Они располагались в миксоидной матрице. Иммуногистохимическое исследование показало, что опухолевые клетки окрашены положительно на белок S100 [3]. Авторы считают данное наблюдение седьмым из представленных ранее шванном перикарда и вторым наблюдением роста опухоли из перикарда в районе левого предсердия.

Первичная злокачественная шваннома сердца (табл. 2). Доброкачественные шванномы сердца необходимо дифференцировать с первичными злокачественными шванномами (синонимы: зло- 


\section{Первичные злокачественные шванномы сердца}

\section{Primary malignant schwannomas of the heart}

\begin{tabular}{|c|l|l|c|c|}
\hline № & \multicolumn{1}{|c|}{ Автор и год публикации } & \multicolumn{1}{|c|}{ Локализация } & Пол & Возраст \\
\hline 1 & Dammert K. et al., 1955 & - & М & 52 года \\
\hline 2 & Siguier F. et al., 1964 & Перикард & - & - \\
\hline 3 & Лихачева A.A. c соавт., 1977 & Правое предсердие & Ж & 7 лет \\
\hline 4 & Gelfand E.T. et al., 1977 & Правое предсердие & Ж & 14 лет \\
\hline 5 & Ursell P.C. et al., 1982 & Правый желудочек & - & - \\
\hline 6 & Morishita T. et al., 1988 & Левый желудочек & Ж & 30 лет \\
\hline 7 & Guschmann M., Weng Y., 1996 & Правые предсердие и желудочек & Ж & 51 год \\
\hline 8 & Bottio T., Gerosa G., 2005 & Перикард & М & 51 год \\
\hline 9 & Rahman M. et al., 2006 & - & М & 32 года \\
\hline 10 & D'Amato N. et al., 2010 & Перикард & М & 60 лет \\
\hline 11 & Cho W.C. et al., 2012 & Левый желудочек & Ж & 32 года \\
\hline 12 & Prifti E. et al., 2014 & Правое предсердие & М & 16 лет \\
\hline 13 & Sun J. et al., 2014 & Митральный клапан & М & 23 мес. \\
\hline
\end{tabular}

качественная неврилеммома, нейрофибросаркома, злокачественная опухоль периферических нервных оболочек - MPNST), которые бывают у лиц обоего пола чаще в возрасте от 20 до 50 лет [9]. Только в единичных наблюдениях описаны такие опухоли у детей. Первичная злокачественная опухоль оболочки периферического нерва сердца обнаружена у 23-месячного ребенка [44], у семилетней девочки [1], у 14-летней девочки [12] и у 16-летнего мальчика [32].

Злокачественные шванномы чаще возникают из нервов с правой стороны сердца, особенно в правом предсердии. Однако они могут быть и в левом предсердии, и в левом желудочке сердца [28]. Эти авторы выявили только три случая первичной злокачественной шванномы сердца в Японии.

Ursell et al. привели результаты исследования опухоли правого желудочка сердца. При световой микроскопии был поставлен гистологический диагноз - нейрофиброма сердца. Однако это был ошибочный диагноз, так как при электронной микроскопии ультраструктура опухоли соответствовала злокачественной шванноме [45].

У 30 -летней женщины была одышка при напряжении, общая усталость и лихорадка. Двухмерная эхокардиография показала перикардиальный выпот большого объема и наличие опухоли между боковой стенкой левого желудочка и эпикардом. На основании гистологического исследования удаленной опухоли был поставлен диагноз «злокачественная шваннома левого желудочка сердца» [28].

Злокачественная шваннома у 51-летнего мужчины клинически проявлялась тахикардией, болью в груди и одышкой. Компьютерная и магнитно-резонансная томографии в области сердца выявили образование размером 18 см, которое было связано с перикардом.
Сердце было полностью окружено этими массами и смещено вверх и вперед. Полости левого и правого предсердий деформированы. Видимого проникновения в миокард не отмечено. Образование было частично удалено. Патологоанатомическое исследование выявило опухоль массой 2200 г, серо-белого цвета на разрезе. В центральных зонах опухоль состояла из фиброзной ткани, а по периферии были густые скопления клеток, среди которых встречались митозы. Иммуногистохимически в опухоли была положительная реакция на CD56 и виментин, а белок S-100 не выявлен. Опухоль классифицировали как злокачественную шванному [5].

Шестидесятилетний мужчина, у которого в анамнезе была артериальная гипертензия, жаловался на одышку в покое, ортопноэ, нарушения ритма, загрудинные боли при вдохе. Электрокардиография: синусовая тахикардия и депрессия ST-сегмента. Рентгенография грудной клетки: увеличение размеров сердца и плевральный выпот. Двухмерная трансторакальная эхокардиография: наличие эхо-свободных зон спереди и сзади сердца; полость левого предсердия деформирована образованием, примыкающим к свободной стенке левого желудочка и задней стенке левого предсердия. Компьютерная томография выявила обширные массы, растущие из перикарда. Магнитно-резонансная томография показала наличие образования с плотной и неоднородной структурой $(5,2 \times 7 \times 11 \mathrm{~cm})$; это образование было плотно фиксировано к перикарду. Во время операции было выполнено только частичное удаление опухоли. Гистологической особенностью была различная степень плотности расположения опухолевых клеток, имевших веретенообразную форму. Многие клетки были в состоянии митоза. В связи с тем что тест на CD56 был положительным, опухоль классифицирована 
как злокачественная опухоль периферических нервных оболочек (MPNST). Проводили адъювантную лучевую терапию и химиотерапию. Однако через несколько месяцев после операции пациент неожиданно скончался [8].

Бывают множественные злокачественные шванномы сердца. M. Guschmann и Y. Weng опубликовали наблюдение, в котором у 51-летней женщины, жаловавшейся на ночную одышку, при эхокардиографическом исследовании были обнаружены две внутрисердечные опухоли. Гистологическое и иммуногистохимическое исследование удаленных образований показало, что у женщины были злокачественные шванномы [14].

Злокачественные шванномы в сердце могут быть не только первичными опухолями, но и представлять собой метастазы. У 31 -летней женщины, главной жалобой которой была боль в спине, при эхокардиографии выявлена опухоль левого предсердия, предположительно миксома. Ангиография отчетливо показала большое образование, во время диастолы пролабирующее из левого предсердия в левый желудочек. Рентгенография крестца также выявила наличие опухоли. Результаты исследования биоптатов, взятых из опухоли крестцового сплетения, показали злокачественную невреному. Несмотря на интенсивную химиотерапию, возникли множественные метастазы, и пациентка умерла через четыре месяца после поступления в клинику. При аутопсии в левом предсердии были найдены три опухоли, гистологическое исследование которых показало, что они представляют собой метастазы злокачественной неврилеммомы, первичная локализация которой была в сакральном сплетении [24]. Представлено наблюдение, в котором у 34-летнего мужчины был метастаз в сердце злокачественной шванномы [26].

Макроскопическая морфология шванном сердца. Доброкачественные шванномы четко ограничены капсулой от окружающих тканей, как правило, имеют яйцевидную форму, плотно-эластическую консистенцию, размеры от $6 \times 4$ см до $12 \times 8$ см и вес от 70 до 360 г [43]. Их поверхность блестящая, желто-коричневого цвета, на разрезе могут быть кистозные полости.

Злокачественные шванномы сердца не имеют четких границ, характеризуются инфильтрирующим ростом. Поэтому их не удается полностью удалить при операции, хотя удаленные части злокачественной шванномы сердца достигают гигантских размеров [5]. Макроскопически злокачественные шванномы сердца бледно-желтого цвета, мягкой консистенции [28].

Гистологическая классификация доброкачественных шванном. С точки зрения морфологии и клиники опухоли из оболочки периферических нервов являются одними из самых разнообразных новообразований человека. При диагностике таких опухолей, в частности шванном, часто допускаются ошибки. Виды доброкачественных шванном: 1) обычная шваннома, гистологически доброкачественная опухоль; 2) клеточная шваннома, гистологически имеет сходство со злокачественной опухолью оболочки периферических нервов (MPNST); 3) плексиформная шваннома, возникающая в детском возрасте и имитирующая MPNST; 4) меланотическая шваннома, часто принимаемая за меланому. Псаммоматозная форма последней часто ассоциируется с комплексом Карней [23].

Гистологическая характеристика доброкачественных шванном. Микроскопически они отличаются от других опухолей нервных оболочек тем, что состоят исключительно из клеток Шванна, а периневральные клетки и фибробласты отсутствуют. К диагностическим особенностям относится наличие фиброзной капсулы и гиалиноза стенки артерий.

В 1910 году уругвайский патологоанатом Хосе Хуан Верокаи (Jose Juan Verocay, 1876-1927), работая в Институте патологии Пражского университета, подробно описал своеобразное выравнивание ядер по параллельным рядам опухолевых клеток в виде частокола или палисада. Эти ряды чередовались с прозрачными зонами, лишенными ядер. Более поздние исследователи назвали эти структуры тельцами Верокаи, а опухоли - шванномами типа Верокаи [47].

Таким образом, классическая гистологическая картина доброкачественных шванном впервые была описана уругвайским патологоанатомом Хосе Хуан Верокаи в 1910 году и шведским исследователем Нилс Рагнар Эжен Антони в 1920 году. Эти опухоли могут быть представлены двумя типами: шваннома типа Верокаи (тип А по Антони) и фасцикулярного типа (тип В по Антони). При типе А имеются компактные структуры с веретенообразными клетками. Эти клетки могут образовывать палисадные структуры и так называемые тельца Верокаи. Напротив, при типе В опухоль относительно гипоцеллюлярна, но богата коллагеновыми волокнами и макрофагами. При фасцикулярном типе клетки опухоли округлой формы, вместе с волокнами они образуют сетчатые структуры [43]. Исходя из своей природы, шваннома имеет анатомическую связь с нервными структурами. Поэтому сам нерв почти всегда входит в состав опухоли [31].

Гистологическая характеристика злокачественных шванном. У злокачественных шванном сердца фиброзная капсула отсутствует или она плохо выражена и прерывистая. Клетки опухоли полиморфны, округлой или вытянутой формы, встречаются многоядерные симпласты. В злокачественных шванномах, в отличие от доброкачественных, встречаются множественные митозы. Стенка сосудов может быть 
гиалинизирована. Вместе с тем гистологическая картина злокачественных шванном может быть сходна с доброкачественными шванномами. Потому для уверенной идентификации злокачественной шванномы требуется проведение иммуногистохимической дифференциации [8].

Иммуногистохимическая дифференциация доброкачественных и злокачественных шванном. Белок S-100 содержится только в клетках Шванна и меланоцитах [42]. Иммуногистохимический метод выявления белка S-100 используют для дифференциальной диагностики доброкачественных шванном, в которых он присутствует, от злокачественных шванном, в которых он отсутствует или содержится в незначительном количестве. Интенсивное диффузное и равномерное окрашивание белка S-100 подтверждает диагноз доброкачественной шванномы [10, 15, 31], а положительная реакция на CD56 свидетельствует о злокачественной шванноме сердца $[5,8]$.

В связи с тем что опухоли периферических нервов, несмотря на ограниченный набор клеточных составляющих, имеют относительно разнообразное гистологическое строение, возникает необходимость в дифференциации шванномы от нейрофибромы и ганглионейромы [40]. Такой онкомаркер, как кальретинин, используемый для диагностики мезотелиомы, адренокортикальной карциномы или синовиальной саркомы, оказался полезным для дифференциальной диагностики шванном и нейрофибром. Из 25 шванном 24 (96\%) показали умеренное или сильное диффузное окрашивание кальретинина, в то время как только 3 (7\%) из 42 нейрофибром показали очаговое слабое или умеренное окрашивание этого онкомаркера [10].

Клиническая картина. При доброкачественных шванномах сердца могут отсутствовать жалобы больных или какая-либо симптоматика [25]. Nakamura et al. описали такую бессимптомную неврилеммому сердца, случайно обнаруженную у 33-летней женщины. Опухоль располагалась на передней поверхности правого предсердия и через межпредсердную борозду распространялась к правой верхней легочной вене. В условиях искусственного кровообращения опухоль была полностью резецирована и проведена реконструкция правого предсердия, межпредсердной перегородки, левого предсердия и правой верхней легочной вены [29].

Симптоматика и при доброкачественных, и при злокачественных шванномах неспецифическая и зависит от их расположения. Опухоль может вызывать внешнюю компрессию и перикардиальный выпот, когда она расположена в стенке предсердия или в полости перикарда. Может произойти обструкция клапанов, когда опухоль находится в полости предсердий. Симптомы также зависят от размера, темпа роста и определяются топографией расположения. Наиболее распространенными клиническими симптомами являются боль в груди, одышка, ортопноэ, периферические отеки, обмороки и аритмии. Изредка бывают признаки сдавления нерва [49].

Клиническая картина при перикардиальных шванномах также неспецифическая. Пациенты жаловались на кашель [50] и боль в груди [3, 7]. В одном-единственном наблюдении со злокачественной формой перикардиальной шванномы пациент 60 лет жаловался на одышку, ортопноэ, боли в груди и нарушения ритма [8]. В двух наблюдениях перикардиальные шванномы были обнаружены случайно у пациентов с кардиомегалией при рентгенографии грудной клетки [16].

Из поздних осложнений у больных со шванномами сердца известны: обструкция оттока из правого желудочка сердца, тромбоэмболия, сердечная недостаточность и внезапная смерть [43].

Диагностика. Новообразования сердца визуализируют различными методами. Эхокардиография обычно является первым методом из-за ее неинвазивного характера. Посредством этого метода удается определить размер опухоли, форму, место прикрепления и подвижность. Тем не менее магнитно-резонансная томография обеспечивает более высокое разрешение и является лучшим методом для получения характеристики опухолевой ткани и ее топографии и васкуляризации. Этот метод помогает заподозрить шванному, особенно если опухоль тесно связана с правым предсердием и межпредсердной перегородкой [39]. Если имеются противопоказания для проведения магнитно-резонансной томографии, например, пациенты, страдающие клаустрофобией или пациенты с имплантированным кардиостимулятором или кардиодефибриллятором, то альтернативным методом является компьютерная томография, которая обеспечивает определение кальцификации и визуализации опухоли по отношению к коронарным артериям [22]. Коронарную артериографию необходимо выполнять у пациентов, у которых имеется риск коронарной болезни сердца [43].

Все нейрогенные опухоли имеют общие визуальные признаки. Поэтому окончательный [31] диагноз может быть установлен только на основании гистологического и иммуногистохимического исследования опухоли [49].

Лечение. В настоящее время основой лечения является радикальная хирургическая резекция опухоли. Это необходимо для предотвращения опасных для жизни осложнений, таких как компрессия, эмболизация, обструкция клапанов и внезапная смерть, а также рецидива образования [43].

При доброкачественных шванномах полное удаление опухоли, как правило, вполне достижимо. Тем не менее в литературе имеется сообщение о час- 
тичном удалении доброкачественной шванномы у 57-летней женщины, так как она плотно прилегала к передней межжелудочковой ветви левой коронарной артерии, что не позволило выполнить полное удаление опухоли [37]. По мнению авторов, это первый случай доброкачественной шванномы левого желудочка сердца у взрослого.

Во время резекции опухоли необходимо: 1) подготовить адекватное операционное поле без чрезмерного изменения положения сердца для обеспечения полной резекции опухоли без его значительного повреждения, особенно если операция выполняется без искусственного кровообращения; 2) провести реконструкцию дефектов после резекции опухоли с использованием ксеноперикарда или аутоперикарда [17].

Стенку предсердия реконструируют с помощью заплаты из различных материалов [43]. После удаления гигантской шванномы левого желудочка сердца может потребоваться последующая коронарная реконструкция [24].

В одной из публикаций [49] сообщается о том, что шваннома перикарда была удалена посредством видеоассистированной торакоскопии. У 48-летней женщины наблюдалось прогрессирование бронхиальной астмы, стесненности в груди и одышки при нагрузках. Рентгенография грудной клетки выявила расширение средостения и кардиомегалию. Компьютерная томография обнаружила хорошо видимый однородный узел в области перикарда правого предсердия размером 2,5 × 2,6 см. Полную хирургическую резекцию опухоли проводили с помощью VATS. Интраоперационно опухоль инкапсулирована, с гладкой поверхностью, серо-розового цвета, плотной консистенции и обильно васкуляризирована. Резецированная поверхность опухоли имела неоднородный желто-белый вид с очаговым кровоизлиянием. При гистологическом исследовании опухоль была с хорошо выраженной капсулой и состояла из веретенообразных клеток, которые в одних зонах были многочисленными, а в других была гипоцеллюлярность. Кроме того, наблюдались многочисленные гиалинизированные сосуды. Иммуногистохимическое окрашивание показало, что опухолевые клетки имеют положительную реакцию на белок S-100, что окончательно подтверждало диагноз «перикардиальная шваннома». Послеоперационные осложнения и рецидив через год наблюдения отсутствовали.

Прогноз. При доброкачественной шванноме сердца прогноз отличный, без необходимости адъювантной терапии [43]. Прогноз при злокачественных шванномах сердца плохой. Полное удаление таких опухолей не удается. Адъювантная лучевая терапия и/или химиотерапия носят только паллиативный характер. При невозможности радикального уда- ления злокачественных шванном перспективным направлением может явиться удаление сердца для резекции опухоли и реконструкции поврежденных тканей и образовавшихся дефектов с последующей реимплантацией сердца в ортотопическую позицию, а при невозможности выполнения данной операции единственным выходом является трансплантация донорского сердца. Однако опыт пересадки сердца при злокачественных новообразованиях ограничен из-за высокого риска рецидива опухоли или метастазирования при лечении иммуносупрессивными препаратами [8].

Мы располагаем наблюдением пациентки 73 лет, которой в условиях искусственного кровообращения и фармако-холодовой кардиоплегии было удалено образование правого предсердия с частичной резекцией свободной стенки правого предсердия и межпредсердной перегородки, оказавшейся при гистологическом и гистохимическом исследовании доброкачественной шванномой. Это наблюдение является девятым случаем в мировой практике при локализации доброкачественной шванномы в правом предсердии.

Авторы заявляют об отсутствии конфликта интересов.

The authors declare no conflict of interest.

\section{СПИСОК АИТЕРАТУРЫ / REFERENCES}

1. Лихачева АА, Каркашина НС, Бурматов НП. Злокачественная неврилеммома сердца у 7-летней девочки. Вопросы охраны материнства и детства. 1977; 22 (9): 81-83. Lihacheva AA, Karkashina NS, Burmatov NP. Zlokachestvennaya nevrilemmoma serdca $\mathrm{u}$ 7-letnej devochki. Voprosy ohrany materinstva i detstva. 1977; 22 (9): 81-83.

2. Петровский БВ, Константинов БА, Нечаенко МА. Первичные опухоли сердца. Российская академия медицинских наук. М.: Медицина, 1997: 152. Petrovskij BV, Konstantinov BA, Nechaenko MA. Pervichnye opuholi serdca. Rossijskaya akademiya medicinskih nauk. M.: Medicina, 1997: 152.

3. Almobarak AA, Alshammari A, Alhomoudi RI, Eshaq AM, Algain SM, Jensen EC et al. Benign Pericardial Schwannoma: Case Report and Summary of Previously Reported Cases. Am J Case Rep. 2018 Jan 24; 19: 90-94.

4. Bizzarri F, Mondillo S, Tanganelli P, Lisi G, Guerrini F, Ammaturo $T$ et al. A primary intracavitary right atrial neurilemoma. J Cardiovasc Surg (Torino). 2001 Dec; 42 (6): 777-779.

5. Bottio T, Gerosa G. Clinical-pathologic conference in cardiac surgery: malignant schwannoma of the heart. $J$ Thorac Cardiovasc Surg. 2005 Jul; 130 (1): 202-205. DOI: $10.1016 / \mathrm{j} . j$ tcvs.2004.11.060.

6. Cho WC, Jung SH, Lee SH, Bang JH, Kim J, Lee JW. Malignant peripheral nerve sheath tumor arising from the left ventricle. J Card Surg. 2012 Sep; 27 (5): 567570. doi: 10.1111/j.1540-8191.2012.01480.x. 
7. Chung JH, Jung JS, Lee SH, Kim KT, Lee K, Lee SH. Resection of Intrapericardial Schwannoma Co-Existing with Thymic Follicular Hyperplasia through Sternotomy without Cardiopulmonary Bypass. Korean J Thorac Cardiovasc Surg. 2014 Jun; 47 (3): 298-301. doi: 10.5090/kjtcs.2014.47.3.298.

8. D'Amato $N$, Correale $M$, Ireva $R$, Di Biase $M$. A rare cause of acute heart failure: malignant schwannoma of the pericardium. Congest Heart Fail. 2010 Mar-Apr; 16 (2): 82-84. doi: 10.1111/j.1751-7133.2009.00124.x.

9. Dammert $K$, Elfving $G$, Halonen PI. Neurogenic sarcoma in the heart. Am Heart J. 1955; 49 (5): 794-800.

10. Fine $S W$, McClain $S A$, Li M. Immunohistochemical staining for calretinin is useful for differentiating schwannomas from neurofibromas. Am J Clin Pathol. 2004 Oct; 122 (4): 552-559. DOI: 10.1309/AGBG-TBRJ-4W0BC7LN.

11. Forbes AD, Schmidt RA, Wood DE, Cochran RP, Munkenbeck $F$, Verrier ED. Schwannoma of the left atrium: diagnostic evaluation and surgical resection. Ann Thorac Surg. 1994 Mar; 57 (3): 743-746.

12. Gelfand ET, Taylor RF, Hendin D, Akabutu J, Callaghan JC. Melanotic malignant schwannoma of the right atrium. J Thorac Cardiovasc Surg. 1977 Nov; 74 (5): 808-812.

13. Gleason TH, Dillard DH, Gould VE. Cardiac neurilemoma. N Y State J Med. 1972; 72: 2435-2436.

14. Guschmann M, Weng $Y$. Primary multiple malignant schwannoma of the heart a rarity. Pathologe. 1996 May; 17 (3): 222-226.

15. Early SA, McGuinness J, Galvin J, Kennedy M, Hurley J. Asymptomatic schwannoma of the heart. J Cardiothorac Surg. 2007 Jan 4; 2: 1. DOI: 10.1186/1749-8090-2-1.

16. Hashimoto T, Eguchi S, Nakayama T, Ohzeki H, Hayashi J. Successful removal of massive cardiac neurilemma with cardiopulmonary bypass. Ann Thorac Surg. 1998; 66: 553-555.

17. Hwang SK, Jung SH. Schwannoma of the heart. Korean $J$ Thorac Cardiovasc Surg. 2014 Apr; 47 (2): 141-144. doi: 10.5090/kjtcs.2014.47.2.141.

18. Hussaim R, Neligan MC. Metastatic malignant schwannoma in the heart. Ann Thorac Surg. 1993; 56: 374-375.

19. Ishikawa K, Hirata S, Fukuzumi N. Malignant neurilemmoma of left atrium. Br Heart J. 1982 Jan; 47 (1): 94-97.

20. Jassal DS, Legare JF, Cummings B, Arora RC, Raza A, Crowell $R$, Hirsch G. Primary cardiac ancient schwannoma. J Thorac Cardiovasc Surg. 2003; 125 (3): 733-735.

21. Jung JC, Chang HW, Kim KH. An unusual presentation of schwannoma in the interatrial space. Korean $J$ Thorac Cardiovasc Surg. 2015 Feb; 48 (1): 95-97. doi: 10.5090/ kjtcs.2015.48.1.95.

22. Koujanian S, Pawlowicz B, Landry D, Alexopoulou L, Nair $V$. Benign cardiac schwannoma: A case report, Human Pathology: Case Reports, 8 (24), 2017.

23. Kurtkaya-Yapicier O, Scheithauer B, Woodruff JM. The pathobiologic spectrum of Schwannomas. Histol Histopathol. 2003 Jul; 18 (3): 925-934. doi: 10.14670/HH18.925.

24. La Francesca S, Gregoric ID, Cohn WE, Frazier OH. Successful resection of a primary left ventricular schwan- noma. Ann Thorac Surg. 2007 May; 83 (5): 1881-1882. DOI: $10.1016 /$ j.athoracsur.2006.12.012.

25. Marchevsky AM. Mediastinal tumors of peripheral nervous system origin. Semin Diagn Pathol. 1999 Feb; 16 (1): 65-78.

26. Menezes Júnior Ada S, Greco OT, Fiorini M, Pavarino P, Corbucci H, Caixeta AM. Malignant schwannoma metastasizing to the heart. Arq Bras Cardiol. 1992 Jan; 58 (1): 35-39.

27. Monroe B, Federman M, Balogh K. Cardiac neurilemoma. Report of a case with electron microscopic examination. Arch Pathol Lab Med. 1984 Apr; 108 (4): 300-304.

28. Morishita T, Yamazaki J, Ohsawa H, Uchi T, Kawamura Y, Okuzumi K et al. Malignant schwannoma of the heart. Clin Cardiol. 1988 Feb; 11 (2): 126-130.

29. Nakamura K, Onitsuka T, Yano M, Yano Y. Surgical resection of right atrial neurilemoma extending to pulmonary vein. Eur J Cardiothoracic Surg. 2003; 24: 840-842.

30. Oguma F, Kasuya S, Takeuchi Y, Ito F, Sakashita I, Fukuda T. Malignant schwannoma of the heart. Nihon Kyobu Geka Gakkai Zasshi. 1987 Aug; 35 (8): 1187-1191.

31. Pilavaki M, Chourmouzi D, Kiziridou A, Skordalaki A, Zarampoukas $T$, Drevelengas $A$. Imaging of peripheral nerve sheath tumors with pathologic correlation: pictorial review. Eur J Radiol. 2004 Dec; 52 (3): 229-239. DOI: 10.1016/j.ejrad.2003.12.001.

32. Prifti E, Baboci A, Ikonomi M. A giant cardiac malignant peripheral nerve sheath tumor presenting with total obstruction of the superior vena cava. Ann Thorac Surg. 2014 Jan; 97 (1): e7-9. doi: 10.1016/j.athoracsur.2013.08.044.

33. Rahman M, Cook DS, Ellis G, O’keefe PA. Malignant peripheral nerve sheath tumor of the heart. Asian Cardiovasc Thorac Ann. 2006 Oct; 14 (5): 425-427. DOI: 10.1177/021849230601400517.

34. Rajesh GN, Raju D, Haridasan V, Sajeev CG, Krishnan $M N$, Rajesh S, Kuriakose KM. Intrapericardial schwannoma presenting as acute coronary syndrome. J Am Coll Cardiol. 2013 Dec 24; 62 (25): e527. doi: 10.1016/j.jacc.2013.06.072.

35. Restrepo CS, Vargas D, Ocazionez D, Martínez-Jiménez S, Betancourt Cuellar SL, Gutierrez FR. Primary pericardial tumors. Radiographics. 2013 Oct; 33 (6): 1613-1630. doi: 10.1148/rg.336135512.

36. Rodriguez FJ, Folpe AL, Giannini C, Perry A. Pathology of peripheral nerve sheath tumors: diagnostic overview and update on selected diagnostic problems. Acta Neuropathol. 2012 Mar; 123 (3): 295-319. doi: 10.1007/ s00401-012-0954-z.

37. Sevimli S, Erkut B, Becit N, Aksakal E, Polat P. Primary benign schwannoma of the left ventricle coursing under the left anterior descending artery. Echocardiography. 2007 Nov; 24 (10): 1093-1095. DOI: 10.1111/j.15408175.2007.00529.x.

38. Siguier F, Godeau P, Cabrol C, Calmettes C, Levy R, Benhamou $R$. Malignant neurinoma of the pericardium. Clinical, angiographic and anatomical study. Sem Hop. 1964; 40: 1915-1924.

39. Sirlak M, Uymaz OK, Tasoz R, Erden E, Ozyurda U, Akalin H. Primary benign schwannoma of the heart. Cardiovasc Pathol. 2003; 12 (5): 290-292. 
40. Skovronsky DM, Oberholtzer JC. Pathologic classification of peripheral nerve tumors. Neurosurg Clin N Am. 2004 Apr; 15 (2): 157-166. DOI: 10.1016/j.nec.2004.02.005.

41. Son KH, Kim KW, Ahn CB, Choi CH, Park KY, Park CH et al. Surgical Planning by 3D Printing for Primary Cardiac Schwannoma Resection. Yonsei Med J. 2015 Nov; 56 (6): 1735-1737. doi: 10.3349/ymj.2015.56.6.1735.

42. Stefansson K, Wollmann R, Jerkovic M. S-100 protein in soft tissue tumours derived from Schwann cells and melanocytes. Am J Pathol. 1982; 106: 261-268.

43. Stolf NA, Santos GG, Sobral ML, Haddad VL. Primary schwannoma of the right atrium: successful surgical resection. Clinics (Sao Paulo). 2006 Feb; 61 (1): 87-88. DOI: /S1807-59322006000100016.

44. Sun J, Chen S, Fan R. Primary cardiac malignant peripheral nerve sheath tumor in a 23 -month-old infant. Cardiovasc Pathol. 2014 Jul-Aug; 23 (4): 248-250. doi: 10.1016/j.carpath.2014.03.008.

45. Ursell PC, Albala A, Fenoglio JJ Jr. Malignant neurogenic tumor of the heart. Hum Pathol. 1982 Jul; 13 (7): 640-645.

46. Wang W, Cui M, Ma HX, Zhang H, Zhang ZH, Cui YB. A large schwannoma of the middle mediastinum: A case report and review of the literature. Oncol Lett. 2016 Mar; 11 (3): 1719-1721. DOI: 10.3892/ol.2016.4148.

47. Wippold FJ, Lämmle M, Anatelli F, Lennerz J, Perry A. Neuropathology for the Neuroradiologist: Palisades and Pseudopalisades. American Journal of Neuroradiology. November 2006; 27 (10): 2037-2041.

48. Wippold FJ, Lubner M, Perrin RJ, Lämmle M, Perry A. Neuropathology for the Neuroradiologist: Antoni A and Antoni B Tissue Patterns. American Journal of Neuroradiology. October 2007; 28 (9): 1633-1638. DOI: https:// doi.org/10.3174/ajnr.A0682.

49. Yun PJ, Huang TW, Li YF, Chang H, Lee SC, Kuo YL. Symptomatic pericardial schwannoma treated with video-assisted thoracic surgery: a case report. $J$ Thorac Dis. 2016 May; 8 (5): E349-352. doi: 10.21037/ jtd.2016.03.40.

50. Zhang $X H$, Wang $Y$, Quan $X Y$, Liang $B$. Benign pericardial schwannoma in a Chinese woman: a case report. BMC Cardiovasc Disord. 2013 Jun 24; 13: 45. doi: 10.1186/1471-2261-13-45.

Статья поступила в редакичию 5.04.2019 2. The article was submitted to the journal on 5.04.2019 